\title{
Air Pressure-Assisted Centrifugal Dewatering of Concentrated Fine Sulfide Particles
}

\author{
R. Asmatulu \\ Mechanical Engineering Department, Wichita State University, 1845 Fairmount, Wichita, KS 67260-0133, USA \\ Correspondence should be addressed to R. Asmatulu, ramazan.asmatulu@wichita.edu
}

Received 19 July 2010; Revised 9 March 2011; Accepted 28 March 2011

Academic Editor: R. Amano

Copyright () 2011 R. Asmatulu. This is an open access article distributed under the Creative Commons Attribution License, which permits unrestricted use, distribution, and reproduction in any medium, provided the original work is properly cited.

An air pressure-assisted centrifugal dewatering method was developed and used for the dewatering of concentrated finesulfide particles, such as sphalerite, galena, and chalcopyrite. This filtration method was mainly designed to increase the filtration rate during the drainage cycle and, hence, produce drier filter cakes, which in turn could reduce the cost and emission problems/concerns of thermal dryers in the preparation plants. Several dewatering parameters, including applied pressure, centrifugal force ( $G$-force), spin time, cake thickness, and surface hydrophobization, were tested to optimize the processing conditions. Test results showed that, at higher air pressure and centrifugal force, the cake moisture reduction was more than $70 \%$, depending on the testing conditions. As a result, it can be-concluded that the novel filtration method effectively works on the dewatering of fine particles $(-150 \mu \mathrm{m})$.

\section{Introduction}

Solid-liquid separation is a major operation in the removal of solids (products) from a processing solution [1]. It exists in almost every process of the chemical, mineral, and metallurgical processing, pharmaceutical, food, water, waste water, and sludge treatment, and pulp and paper industries [2]. Solid-liquid separation techniques are very diverse and mainly include vacuum, pressure and centrifugal filters, screens, trommels, hydrocyclones, thickeners, classifiers, and reverse osmosis [3]. During the separation process, some surfactants, polymers, and electrolytes can be utilized to make the separation process efficient [4].

The size reduction of sulfide minerals is necessary to separate the valuable minerals from the gangue minerals, such as silicates, carbonates, clay, pyrite, and other sulfides and oxides [2]. Then, sulfide minerals are concentrated from the gangue minerals by using froth flotation, which is a wet separation process [4]. The sulfide flotation occurs below $200 \mu \mathrm{m}$ by adding appropriate xanthate-type collectors and frothers because of the high specific gravity and liberation of the minerals in run-of-mine. The collector molecules are adsorbed on the surface of the mineral and make it hydrophobic, which is a necessary step in separating the collector-coated minerals from the hydrophilic gangue particles. The hydrophobized components can easily attach to air bubbles and rise up to the surface of the pulp. This valuable product is in slurry form and generally contains between $5 \%$ and $25 \%$ solids [2].

Filtration is an unavoidable step in preparation plants after the valuable particles are thickened [5-8]. Filtration methods, such as vacuum, pressure, and centrifuge, are usually inefficient and produce high-moisture-content cakes at lower sizes (below $200 \mu \mathrm{m}$ ). The literature studies show that the moisture content of fine dewatered sulfide minerals is between $10 \%$ and $20 \%$, depending on the applied dewatering methods and particle size [1-4]. For shipping and the smelting process, a further moisture reduction $(5 \%-8 \%)$ by a thermal dryer is required following the filtration step; however, it is a costly process and creates air pollution, such as the emission of fine dust and sulfur dioxide in the exhaust gases. These components can be very hazardous to human health and the environment [5-11].

Although the centrifugal dewatering process has been effectively employed in the filtration of larger-sized particles $(+200 \mu \mathrm{m})$, it is not effective with smaller-sized particles 
$(-200 \mu \mathrm{m})$ [6]. Thus, it is necessary to improve the efficiency of the centrifugal filters for the finer-sized products. In the present study, in order to increase the efficiency of the centrifugal dewatering process, $G$-force and air pressure were combined in one filtration unit and used for the dewatering of concentrated sulfide minerals, such as chalcopyrite, sphalerite, and galena.

\section{Theory}

Centrifugal dewatering is a process of removing the processed water from solids or products by applying high gravitational forces. The centrifugal force, $G$, may be calculated based on the rotational speed (or angular velocity) $\omega$ of the vessel and radius $r$ of the same centrifuge vessel [12-18]:

$$
G=\frac{r \omega^{2}}{g}
$$

In centrifugal dewatering, Darcy's law may be used to determine the fluid flow rate $\mathcal{Q}$ through the filter cake [4]:

$$
Q=\frac{K \Delta P A}{\mu L}
$$

where $K$ is the permeability of the cake, $\Delta P$ is the pressure drop across the cake, $A$ is the filtration area, $\mu$ is the dynamic viscosity of water, and $L$ is the cake thickness. During the filtration period, the pressure drop across the filter cake is determined by the following relationship [9]:

$$
\Delta P=\frac{1}{2} \rho \omega^{2}\left(r_{S}^{2}-r_{0}^{2}\right)
$$

where $\rho$ is the density of the liquid and $r_{0}$ and $r_{S}$ are the radial distances of the free water and the cake surface, respectively, from the rotational axis of a centrifuge. As shown in (3), $\Delta P$ becomes zero when the water on the cake disappears (i.e., $r_{0}=r_{S}$ ). As the water level in the cake decreases further (i.e., $r_{0}>r_{S}$ ), the pressure within the cake becomes lower than the ambient pressure [4]. This may be the fundamental reason why centrifuges cannot produce as low-cake moistures as vacuum or pressure filters for the finer particles. In this model, the pressure $\left(P_{(r)}\right)$ through the radial distance $r$ of a centrifuge can be predicted by the following equation [1921]:

$$
P_{(r)}=\frac{\ln \left(r_{b} / r\right)}{\ln \left(r_{b} / r_{s}\right)} P_{S}+\frac{\rho \omega^{2} r_{b}^{2}}{2}\left[\frac{\ln \left(r_{b} / r\right)}{\ln \left(r_{b} / r_{s}\right)}\left(1-\frac{r_{s}^{2}}{r_{b}^{2}}\right)-\left(1-\frac{r^{2}}{r_{b}^{2}}\right)\right],
$$

where $r_{b}$ is the radial distance to the base of the filter cake and $r_{b}-r_{0}$ is the cake thickness. This expression indicates that the larger the thickness of the layer of water over the cake surface, the higher the $P_{S}$ (pressure at the cake surface) becomes for higher dewatering rates.

Filter cakes have a bundle of fine capillary tubes that contain water molecules [1-5]. In our present model, water trapped in the fine capillaries continuously flows through the filter cake under the applied air pressures, which is the major
TABLe 1: Effects of $G$-force and air pressure on the dewatering of sphalerite sample $(-150 \mu \mathrm{m})$ at $500 \mathrm{G}$-force and $1.5 \mathrm{~cm}$ cake thickness.

\begin{tabular}{lccccc}
\hline $\begin{array}{l}\text { Spin time } \\
(\text { sec. })\end{array}$ & None & 50 & 100 & 200 & 300 \\
\hline 0 & 20.2 & 20.2 & 20.2 & 20.2 & 20.2 \\
30 & 14.8 & 10.1 & 8.9 & 7.4 & 7.2 \\
60 & 14.7 & 9.5 & 8.4 & 6.8 & 6.5 \\
90 & 14.4 & 9.2 & 8.3 & 6.2 & 5.7 \\
120 & 14.2 & 8.8 & 7.9 & 5.9 & 5.4 \\
\hline
\end{tabular}

contribution of the present work [4]. We assumed that only $G$-force may not be sufficient to remove water in the smaller capillaries of the filter cakes. The other studies also agree well with our approach [18-21]. The water molecules in the capillary tubes can be removed when the applied pressure is larger than the capillary pressure $p[4]$ :

$$
p=\frac{2 \gamma_{23} \cos \theta}{r}
$$

where $r$ is capillary radii, $\gamma_{23}$ is the surface tension of the liquid-vapor interface, and $\theta$ is the contact angle at the airwater-solid interface. As shown, $p$ decreases with decreasing $\gamma_{23}$, increasing $\theta$, and $r$ at a contact angle lower than $90^{\circ}$. After the contact angle higher than $90^{\circ}$, this scenario will be exactly opposite.

\section{Experimental}

3.1. Samples. Three different clean sulfide mineralssphalerite, galena, and chalcopyrite-were received from a plant located in Europe. The surfaces of these concentrated mineral particles were oxidized in the water during the delivery process to the laboratory facilities. Thus, in order to regenerate fresh and hydrophobic mineral surfaces, these samples were ball-mill ground for about one minute and then refloated in a Denver flotation cell using $50 \mathrm{~g} / \mathrm{ton}$ of sodium isopropyl xanthate and $75 \mathrm{~g} /$ ton of methylisobutyl carbinol (MIBC) at appropriate pHs [4]. Lime solutions of 9.2, 10.5, and 8.5 were used to adjust the $\mathrm{pH}$ values of sphalerite, chalcopyrite, and galena, respectively. In addition, particle-size distributions of the samples were measured by wet sieve screening prior to the tests. The solid contents of the flotation products were between $20 \%$ and $30 \%$. Based on our experience, surface hydrophobicity improves the dewatering process on the ultrafine particles, so that the reflotation step will allow for the production of lower-moisture-content filter cakes $[4,17]$. Samples received from the flotation process were in the form of slurry, so the solid content of the samples was improved by using a large funnel filter. The centrifugal dewatering tests were conducted on the thickened samples at different $G$-forces, air pressures, cake thicknesses, and spin (or centrifugation) times. 


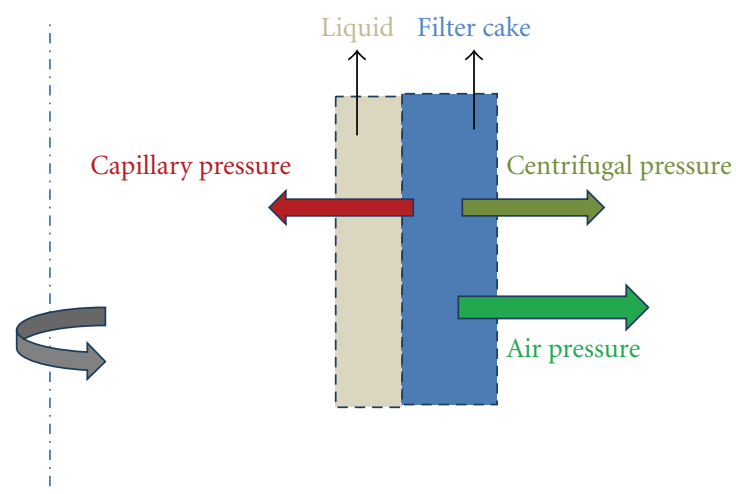

FIGURE 1: Schematic illustration of three acting pressures on the cake in the novel centrifuge at a given moment.

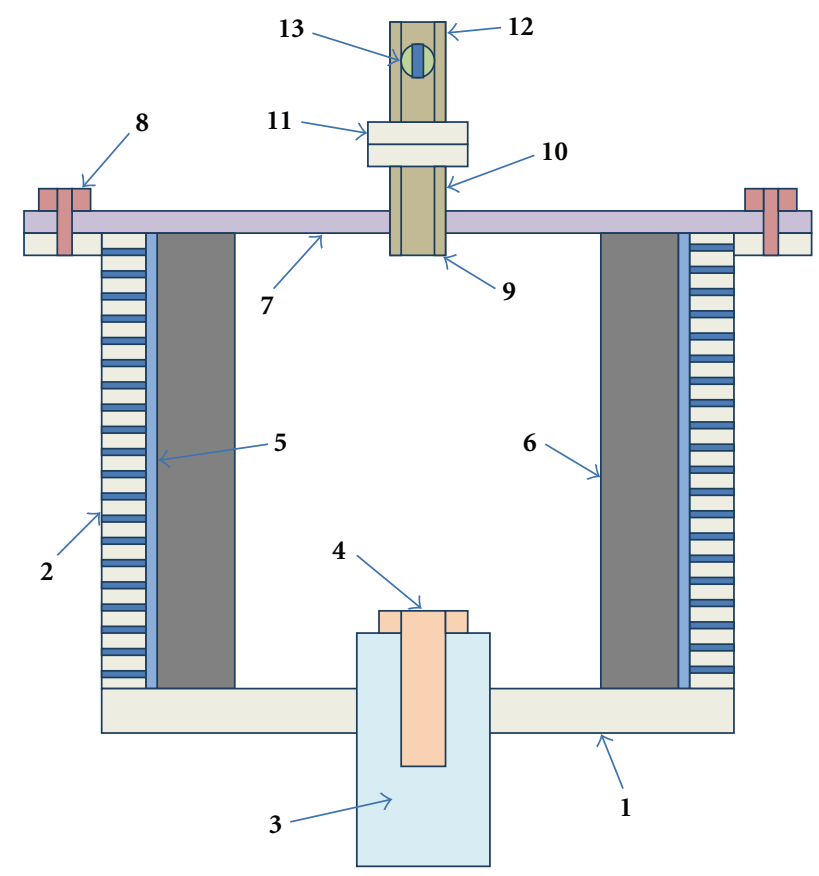

FIGURE 2: Schematic representation of the novel centrifuge with air pressure: (1) vessel, (2) circular holes, (3) rotor of the centrifuge, (4) lager screw, (5) a filter cloth, (6) filter cake, (7) lid, (8) smaller screws, (9) air inlet tubing, (10) flat-polished surface, (11) double-bearing connector, (12) external compressed air line, and (13) on/off valve.

TABLE 2: Effects of $G$-force and air pressure on the dewatering of sphalerite sample $(-150 \mu \mathrm{m})$ at $1,000 \mathrm{G}$-force and $1.5 \mathrm{~cm}$ cake thickness.

\begin{tabular}{lccccc}
\hline $\begin{array}{l}\text { Spin time } \\
(\text { sec.) }\end{array}$ & None & 50 & 100 & 200 & 300 \\
\hline 0 & 20.2 & 20.2 & 20.2 & 20.2 & 20.2 \\
30 & 13.7 & 8.7 & 7.2 & 5.8 & 5.5 \\
60 & 13.7 & 8.4 & 6.8 & 5.1 & 4.2 \\
90 & 13.4 & 7.2 & 6.2 & 4.8 & 3.9 \\
120 & 13.2 & 7.3 & 6.1 & 4.3 & 3.8 \\
\hline
\end{tabular}

TABle 3: Effects of $G$-force and air pressure on the dewatering of sphalerite sample $(-150 \mu \mathrm{m})$ at 2,000 $G$-force and $1.5 \mathrm{~cm}$ cake thickness.

\begin{tabular}{lccccc}
\hline $\begin{array}{l}\text { Spin time } \\
(\text { sec.) }\end{array}$ & None & 50 & 100 & 200 & 300 \\
\hline 0 & 20.2 & 20.2 & 20.2 & 20.2 & 20.2 \\
30 & 13.2 & 8.4 & 7.2 & 5.8 & 5.0 \\
60 & 13.1 & 8.1 & 6.5 & 4.7 & 4.2 \\
90 & 12.8 & 7.2 & 6.1 & 4.5 & 3.5 \\
120 & 12.4 & 7.1 & 5.9 & 4.2 & 3.3 \\
\hline
\end{tabular}


3.2. Method. In the present work, a novel centrifuge filter was designed and constructed for the ultrafine particle dewatering. Its novelty lies in the creation of a high pressure drop across the filter cake using $G$-force and air pressure against the capillary pressure to remove more water (Figure 1). Figure 2 shows the centrifuge vessel 1, into which compressed air was injected to create a pressure drop across the filter cake [4]. The vessel was made of stainless steel with dimensions of $8.9 \mathrm{~cm}$ inside diameter and $7.6 \mathrm{~cm}$ height. When the operation started, it was placed vertically inside a centrifuge machine, which was capable of varying the rpm's of the vessel. The side wall was made of perforated stainless steel with $0.32 \mathrm{~mm}, 0.24 \mathrm{~mm}$, and $1.6 \mathrm{~mm}$ circular holes 2 . The filter vessel was tightened against the rotor 3 of the centrifuge by means of a screw 4 . A filter cloth 5 , which was designed to fit the contour of the centrifuge vessel 1 , was placed inside the vessel. Thickened slurry was then pasted against the filter cloth 5 and the side wall of the filter vessel to form a cake 6 . The filter vessel was covered by a lid 7 , which was tightened against the filter vessel 1 by means of screws 8 . Then, a compressed air inlet tubing 9 was connected at the center of the cover lid 7 . The tubing was terminated by a flatpolished surface 10. A double-bearing connector 11 was used to couple the compressed air inlet tubing 9 with an external compressed air line 12, which was equipped with an on/off valve 13 . The compressed air line carried an airflow meter and a pressure gauge [4].

\section{Results and Discussion}

4.1. Fine Sphalerite Particles. Sphalerite is an important zinc ore mineral with an iron content $((\mathrm{Zn}, \mathrm{Fe}) \mathrm{S})$ and is an attractive zinc metal source in the metallurgical industry. In nature, it is usually associated with other minerals, such as galena, pyrite, and other sulfides, along with calcite, dolomite, and fluorite [10]. In order to liberate these minerals, crushing, grinding, and classifying are often conducted. Then, a flotation process, which is a mineral concentration step using air bubbles, is usually applied to yield the sphalerite minerals from the unwanted gangue minerals [11].

A sphalerite concentrate was tested in the novel centrifugal filtration unit. Table 1 gives the effects of $G$-force and air pressure on the dewatering of the sphalerite sample $(-150 \mu \mathrm{m})$ at $500 \mathrm{G}$-force and $1.5 \mathrm{~cm}$ cake thickness. As shown, moisture content of the thickened samples is approximately $20 \%$. At $30,60,90$, and 120 seconds of spin time and $500 \mathrm{G}$-force, the moisture content values of the samples were $14.8 \%, 14.7 \%, 14.4 \%$, and $14.2 \%$, respectively. No air pressure was applied to the filter cakes in these control tests. In the presence of air pressure, moisture reduction of the filter cakes was further enhanced. For example, at 50, 100, 200 , and $300 \mathrm{kPa}$ air pressure, the moisture contents of the filter cakes were reduced to $8.8 \%, 7.9 \%, 5.9 \%$, and $5.4 \%$ at 120 seconds of spin time, correspondingly.

In order to determine the effects of centrifugal forces, experiments were conducted on the same mineral concentrates at different $G$-forces. Tables 2 and 3 give the effects of $G$-force and air pressure on the dewatering of sphalerite
TABLE 4: Effects of $G$-force and air pressure on the dewatering of chalcopyrite sample $(-150 \mu \mathrm{m})$ at $1,000 \mathrm{G}$-force and $1.5 \mathrm{~cm}$ cake thickness.

\begin{tabular}{lccccc}
\hline $\begin{array}{l}\text { Spin time } \\
(\text { sec.) }\end{array}$ & None & 50 & 100 & 200 & 300 \\
\hline 0 & 22.9 & 22.9 & 22.9 & 22.9 & 22.9 \\
30 & 15.2 & 10.1 & 7.7 & 5.9 & 5.3 \\
60 & 15.2 & 9.9 & 6.9 & 5.1 & 4.3 \\
90 & 15.0 & 9.5 & 6.0 & 4.9 & 4.0 \\
120 & 14.9 & 9.0 & 5.6 & 4.2 & 3.5 \\
\hline
\end{tabular}

TABLE 5: Effects of $G$-force and air pressure on the dewatering of chalcopyrite sample $(-150 \mu \mathrm{m})$ at $1,500 \mathrm{G}$-force and $1.5 \mathrm{~cm}$ cake thickness.

\begin{tabular}{lccccc}
\hline $\begin{array}{l}\text { Spin time } \\
(\text { sec.) }\end{array}$ & None & 50 & 100 & 200 & 300 \\
\hline 0 & 22.9 & 22.9 & 22.9 & 22.9 & 22.9 \\
30 & 15.0 & 10.0 & 7.3 & 5.6 & 5.1 \\
60 & 14.9 & 9.5 & 6.2 & 4.7 & 4.4 \\
90 & 14.8 & 9.1 & 5.5 & 4.6 & 3.6 \\
120 & 14.7 & 8.8 & 5.4 & 4.0 & 3.5 \\
\hline
\end{tabular}

sample $(-150 \mu \mathrm{m})$ at 1,000 and 2,000 $G$-forces and $1.5 \mathrm{~cm}$ cake thickness. As the centrifugal forces were increased on the filter cakes, the moisture content was gradually reduced. At $300 \mathrm{kPa}$ air pressure and 120 seconds of spin time, the moisture content of the filter cakes was reduced from $20.2 \%$ to $3.8 \%$ and $3.3 \%$ at 1,000 and $2,000 \mathrm{G}$-forces, respectively. In addition to $G$-force effects, similar tests were also conducted on different thicknesses of cake samples, and test results show that the thicker cakes have higher moisture contents (results are not shown here).

The size of the zinc sample was finer than many other particles, such as coal particles $(-0.5 \mathrm{~mm})$. In the practical point of view, moisture levels of the fine particles should be higher than those of coarse particles, according to the Laplace equation [4]. However, if one looks at the test results, the moisture content of the zinc mineral is much lower than the coal sample [6]. This is because the specific density of the zinc minerals $\left(4.1 \mathrm{~g} / \mathrm{cm}^{3}\right)$ is significantly higher than that of coal $\left(1.2 \mathrm{~g} / \mathrm{cm}^{3}\right)$, which causes a tighter cake and, hence, a lower moisture content. In addition, the sample was a flotation product, and its surface was hydrophobic, so this can be the other reason for high moisture reductions in the sulfide minerals [5].

4.2. Fine Chalcopyrite Particles. Chalcopyrite (or copper pyrite) is a copper-rich iron sulfide mineral $\left(\mathrm{CuFeS}_{2}\right)$, which is the major source of copper metals. Like other sulfide minerals, chalcopyrite is not usually pure in nature and is often contaminated by a variety of other trace elements, such as $\mathrm{Co}, \mathrm{Ni}, \mathrm{Mn}, \mathrm{Zn}$, and $\mathrm{Sn}$ substituting for $\mathrm{Cu}$ and $\mathrm{Fe}$, as well 
TABLE 6: Effects of $G$-force and air pressure on the dewatering of chalcopyrite sample $(-150 \mu \mathrm{m})$ at $2,000 \mathrm{G}$-force and $1.5 \mathrm{~cm}$ cake thickness.

\begin{tabular}{lccccc}
\hline $\begin{array}{l}\text { Spin time } \\
(\text { sec. })\end{array}$ & None & 50 & 100 & 200 & 300 \\
\hline 0 & 22.9 & 22.9 & 22.9 & 22.9 & 22.9 \\
30 & 15.1 & 9.5 & 6.9 & 6.1 & 6.1 \\
60 & 14.5 & 9.0 & 5.8 & 5.1 & 4.9 \\
90 & 14.1 & 8.4 & 5.7 & 4.6 & 4.1 \\
120 & 14.0 & 8.0 & 5.5 & 4.0 & 3.1 \\
\hline
\end{tabular}

as other oxides minerals. Flotation and other wet separation methods are employed to concentrate the chalcopyrite at a smaller size [10]. Finally, the fine chalcopyrite particles are filtered to remove the processing water for the ongoing processes.

In the present tests, clean chalcopyrite particles were dewatered using the novel dewatering method. Table 4 gives the effects of air pressure on the dewatering of the chalcopyrite sample $(-150 \mu \mathrm{m})$ at $1,000 \mathrm{G}$-force and $1.5 \mathrm{~cm}$ cake thickness. The tests conducted without air pressure reduced the cake moisture from $22.9 \%$ to $15.2 \%$ after 30 seconds of centrifuge time. Longer spin times did not significantly reduce the moisture content of the cakes. In the presence of applied air pressure, however, very low cake moistures were obtained. For example, at 50, 100, 200, and $300 \mathrm{kPa}$ air pressure and 1,000 G-force, the moisture content was reduced from $22.9 \%$ to $9 \%, 5.6 \%, 4.2 \%$, and $3.5 \%$, respectively. According to these test results, it may be concluded that this dewatering process can replace the thermal dryers prior to the next metallurgical processes for matte production.

The same experimental tests were also conducted at 1,500 and 2,000 $G$-forces to determine the $G$-force effects. Tables 5 and 6 show the effects of air pressure on the dewatering of chalcopyrite samples $(-150 \mu \mathrm{m})$ at 1,500 and 2,000 $G$-forces and $1.5 \mathrm{~cm}$ cake thickness. As shown, the higher centrifugal forces only made slight changes in the final moisture content of the filter cakes. This indicates that the 1,000 G-force along with $200 \mathrm{kPa}$ air pressure and 60 seconds of spin time will be enough to produce a filter cake that contains less than $5 \%$ moisture content. This moisture content will provide huge cost savings in transportation of the dewatered chalcopyrite samples.

4.3. Fine Galena Particles. Galena is a natural lead mineral in the form of lead sulfide (PbS) and is one of the most abundant sulfide minerals on the earth's crust. It is often associated with other sulfide (e.g., sphalerite, pyrite, and chalcopyrite) and oxide minerals (e.g., calcite, fluorite, and dolomite) [10]. Galena minerals are usually liberated in a smaller size and then separated from the gangue minerals by the flotation process using xanthate and MIBC in a slightly alkaline $\mathrm{pH}$. Typically, a galena reach flotation product has
TABLE 7: Effects of $G$-force and air pressure on the dewatering of galena sample $(-75 \mu \mathrm{m})$ at $1,000 \mathrm{G}$-force and $1.5 \mathrm{~cm}$ cake thickness.

\begin{tabular}{lccccc}
\hline $\begin{array}{l}\text { Spin time } \\
(\text { sec. })\end{array}$ & \multicolumn{5}{c}{$\begin{array}{c}\text { Cake moisture (\%) } \\
\text { air pressure }(\mathrm{kPa})\end{array}$} \\
\hline 0 & None & 50 & 100 & 200 & 300 \\
30 & 18.0 & 18.0 & 18.0 & 18.0 & 18.0 \\
60 & 13.9 & 9.0 & 7.3 & 5.6 & 4.8 \\
90 & 13.9 & 8.5 & 6.7 & 5.0 & 4.3 \\
120 & 13.8 & 8.3 & 6.3 & 4.5 & 3.9 \\
\hline
\end{tabular}

TABLE 8: Effects of $G$-force and air pressure on the dewatering of galena sample $(-75 \mu \mathrm{m})$ at 2,000 $G$-force and $1.5 \mathrm{~cm}$ cake thickness.

\begin{tabular}{lccccc}
\hline $\begin{array}{l}\text { Spin time } \\
(\text { sec.) }\end{array}$ & None & 50 & 100 & 200 & 300 \\
\hline 0 & 18.0 & 18.0 & 18.0 & 18.0 & 18.0 \\
30 & 12.0 & 8.6 & 6.7 & 4.6 & 4.3 \\
60 & 12.0 & 8.2 & 6.2 & 4.1 & 3.6 \\
90 & 11.8 & 7.7 & 5.9 & 3.5 & 3.2 \\
120 & 11.7 & 7.4 & 5.8 & 3.1 & 2.3 \\
\hline
\end{tabular}

TABLE 9: Effects of $G$-force and air pressure on the dewatering of galena sample $(-75 \mu \mathrm{m})$ at 2,500 $G$-force and $1.5 \mathrm{~cm}$ cake thickness.

\begin{tabular}{lccccc}
\hline $\begin{array}{l}\text { Spin time } \\
(\text { sec.) }\end{array}$ & None & 50 & 100 & 200 & 300 \\
\hline 0 & 18.0 & 18.0 & 18.0 & 18.0 & 18.0 \\
30 & 12.2 & 8.2 & 6.4 & 4.4 & 4.1 \\
60 & 11.8 & 7.8 & 5.9 & 4.0 & 3.2 \\
90 & 11.7 & 7.6 & 5.5 & 3.1 & 2.6 \\
120 & 11.6 & 7.1 & 5.1 & 2.7 & 1.9 \\
\hline
\end{tabular}

very high moisture content, so it needs to be dewatered prior to the ongoing processes [4].

Table 7 shows the effects of air pressure on the dewatering of a clean galena sample $(-75 \mu \mathrm{m})$ at 1,000 $G$-force and $1.5 \mathrm{~cm}$ cake thickness. The initial moisture content of the thickened samples was $18.0 \%$. At 1,000 G-force, the moisture content of fine galena particles was $13.7 \%$ after 120 seconds of spin time. However, at 50, 100, 200, and $300 \mathrm{kPa}$ air pressure, the moisture content of the filter cakes was $8.1 \%$, $6.2 \%, 4.1 \%$, and $3.2 \%$, respectively, following the same spinning time. It was also observed that some filter cakes were nearly dry and did not show the sticking wet particles.

High $G$-forces were also applied on the fine galena sample to determine the effects of centrifugal forces. Tables 8 and 9 provide the effects of $G$-force and air pressure on the dewatering of galena samples $(-75 \mu \mathrm{m})$ at 2,000 and 2,500 Gforce and $1.5 \mathrm{~cm}$ cake thickness. Higher centrifugal force and air pressure greatly reduce the moisture content to $2 \%$. It was also determined that the galena sample always shows a lower 
moisture content than the other samples used in these tests, although it has a smaller particle size. Specific gravity may be the reason for this since the specific density $\left(7.5 \mathrm{~g} / \mathrm{cm}^{3}\right)$ of galena is the highest compared to chalcopyrite $\left(4.2 \mathrm{~g} / \mathrm{cm}^{3}\right)$ and sphalerite $\left(4.1 \mathrm{~g} / \mathrm{cm}^{3}\right)$. It can also be seen that the most of the moisture was removed from the cake in 30 seconds of spin time, which indicates that the kinetics of the fine particle dewatering is fairly high, which in turn will reduce the dewatering time and related costs [1].

Centrifugal dewatering is a widely used method for the separation of solids from liquids in several industries due to higher gravitational forces acting on the particles [12-15]. In this method, if the applied centrifugal force created by the angular velocity of a rotating basket is larger than capillary force (5), liquid in the capillary tubes will be spontaneously removed from the filter cakes [3]. For this reason, the centrifugal filters are performed at high speed for the fine particles to obtain lower moisture-content products. However, higher speeds or centrifugal forces can cause additional problems and maintenance costs. The novel filtration methods can solve these problems of classical centrifugal filters [4]. Also, the improvements obtained using the combination are far superior to those obtained using either air pressure or $G$-force alone, demonstrating a synergistic effect [4]. The synergism observed in the present investigation can be attributed to the creation of a larger pressure drop across the filter cake so that one can take advantage of Darcy's law (2). All the test results produced in the present studies agreed well with the literature studies [18-21].

\section{Conclusions}

It is difficult to remove the free water adhering to the surface of fine particles by current mechanical dewatering methods, such as vacuum, pressure, and centrifugal forces. The major reason is that the finer the particle size, the larger the surface area, and the more difficult it becomes to dewater. Reduction in particle size causes the smallersized capillaries in the filter cakes, which in turn increases the pressure necessary to remove water from the capillaries. Thus, the dewatering of fine mineral particles is one of the most challenging processes in a preparation plant. In this study, a new centrifugal filtration unit was developed to remove the surface moisture of fine sulfide minerals (e.g., chalcopyrite, sphalerite, and galena) at various $G$-forces, air pressures, spin times, and cake thicknesses. Experimental results showed that the moisture content of filter cakes was significantly lower when the air pressure was applied to the centrifugal vessel. Such low moisture should obviate the energy needed for thermal drying, which is a costly method and has considerable environmental concerns. This new method can be applicable to the dewatering of many other organic and inorganic fine particles as well. Consequently, the novel filtration unit can decrease the costs of dewatering, transportation, surface oxidations and leaching of particles, and environmental concerns of the thermal dryers in the fine-particle processing plants.

\section{Acknowledgments}

The author gratefully acknowledges Dr. Yoon and all members of the Center for Advanced Separation Technology (CAST) at Virginia Tech for their support received throughout this research.

\section{References}

[1] K. Sutherland, Filters and Filtration Handbook, Elsevier, 2007.

[2] E. S. Tarleton and R. J. Wakeman, Solid/Liquid Separation: Equipment Selection and Process Design, Elsevier, 1st edition, 2007.

[3] A. Rushton, A. S. Ward, and R. G. Holdich, Solid-Liquid Filtration and Separation Technology, Wiley-VCH, 2nd edition, 2000.

[4] R. Asmatulu, Advanced chemical-mechanical dewatering of fine particles, Ph.D. thesis, Virginia Tech, 2001.

[5] R. Asmatulu, "Removal of moisture from the ultra fine particles using both high centrifugal force and air pressure," Separation Science and Technology, vol. 44, no. 2, pp. 265-274, 2009.

[6] R. Asmatulu, G. Luttrell, and R. H. Yoon, "Hyperbaric centrifugal filtration," International Journal of Coal Preparation and Utilization, vol. 25, pp. 117-127, 2005.

[7] R. Asmatulu, "Enhancement of the dewetability characteristics of fine silica particles," Turkish Journal of Engineering and Environmental Sciences, vol. 26, no. 6, pp. 513-519, 2002.

[8] R. Asmatulu, "Removal of the discoloring contaminants of an East Georgia kaolin clay and its dewatering," Turkish Journal of Engineering and Environmental Sciences, vol. 26, no. 5, pp. 447-453, 2002.

[9] L. Svarovsky, Solid-Liquid Separation, Butterworth Heinemann, 4th edition, 2000.

[10] M. C. Fuerstenau and K. N. Han, Principles of Mineral Processing, Society for Mining Metallurgy \& Exploration (SME), 2003.

[11] R. Rao and J. Leja, Surface Chemistry of Froth Flotation: Reagents and Mechanisms, Kluwer Academic/Plenum Publishers, New York, NY, USA, 2nd edition, 2004.

[12] R. J. Wakeman, "Separation technologies for sludge dewatering," Journal of Hazardous Materials, vol. 144, no. 3, pp. 614619, 2007.

[13] C. P. Chu and D. J. Lee, "Experimental analysis of centrifugal dewatering process of polyelectrolyte flocculated waste activated sludge," Water Research, vol. 35, no. 10, pp. 2377-2384, 2001.

[14] J. R. Pan, C. Huang, M. Cherng, K. C. Li, and C. F. Lin, "Correlation between dewatering index and dewatering performance of three mechanical dewatering devices," Advances in Environmental Research, vol. 7, no. 3, pp. 599-602, 2003.

[15] A. Akcil, X. Q. Wu, and E. K. Aksay, "Coal-gold agglomeration: an alternative separation process in gold recovery," Separation and Purification Reviews, vol. 38, no. 2, pp. 173-201, 2009.

[16] R. H. Yoon and R. Asmatulu, "Methods of improving centrifugal filtration," U.S. patent no. 6,440,316, 2002.

[17] R. Asmatulu, "Improving the dewetability characteristics of hydrophobic fine particles by air bubble entrapments," Powder Technology, vol. 186, no. 2, pp. 184-188, 2008.

[18] C. Veal, S. Nicol, and K. Johnston, "Process for the dewatering of coal and mineral slurries," USA patent no: 5,771,601, 1998.

[19] S. Keles, G. Luttrell, R. H. Yoon, T. Estes, W. Schultz, and P. Bethell, "Development of the centribaric ${ }^{\mathrm{TM}}$ dewatering 
technology," International Journal of Coal Preparation and Utilization, vol. 30, pp. 204-216, 2010.

[20] J. A. Salomon, Design and testing of a hyperbaric horizontal belt filter for fine coal dewatering, M.S. thesis, Virginia Tech, 2007.

[21] S. Keles, Fine coal dewatering using hyperbaric centrifuge, Ph.D. thesis, Virginia Tech, 2010. 

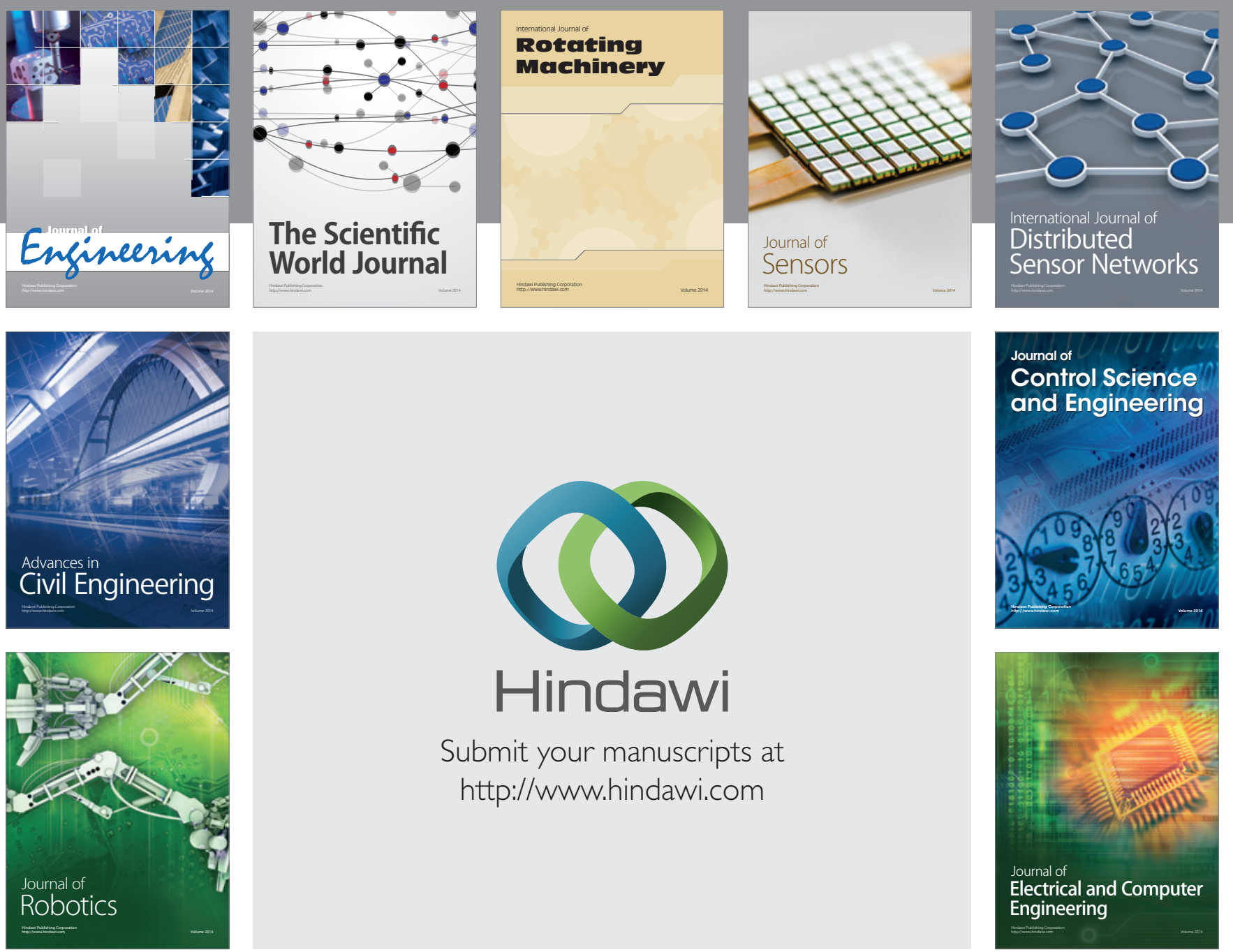

Submit your manuscripts at

http://www.hindawi.com
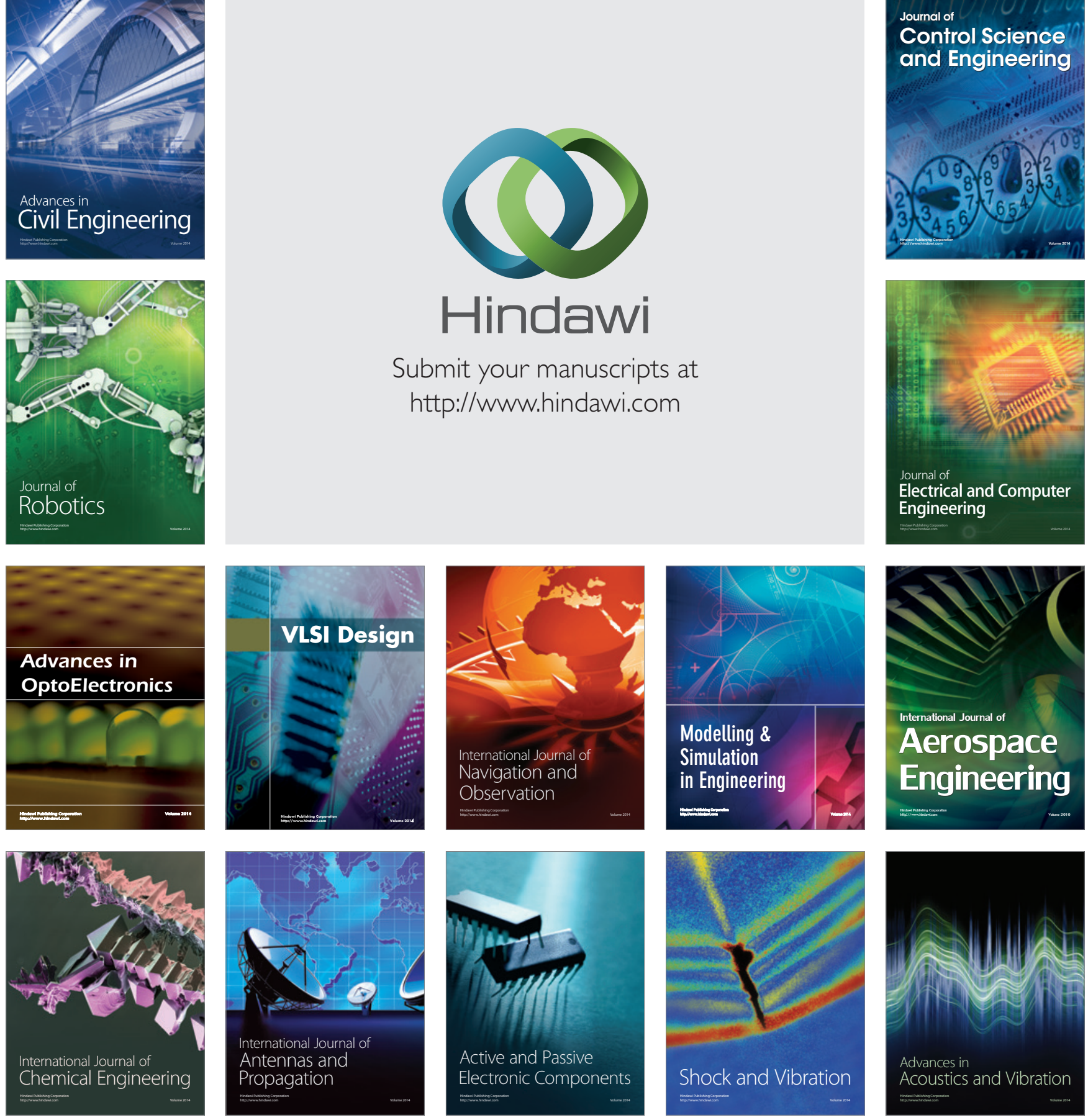